\title{
International Trade Related Decion Making Across Different Managerial Levels: the Case of SMEs
}

\author{
Sigitas Brazinskas ${ }^{1}$, Vida Pipiriené $\dot{2}^{2}$ \\ ${ }^{1}$ Value Development, Vilnius, Lithuania \\ ${ }^{2}$ Department of International Economics and Business Management, Faculty of Business Management, \\ Vilnius Gediminas Technical University, Vilnius, Lithuania \\ E-mails: ${ }^{\text {sigitas.brazinskas@value.lt (corresponding author); }{ }^{2} v i d a . p i p i r i e n e @ v g t u . l t ~}$
}

Received 20 February 2017; accepted 07 April 2017

\begin{abstract}
International trade is an important engine for economies and SMEs to grow and sustain. Despite globalization, regionalization or other processes with a direct impact to international business, SMEs experience a pressure of external and internal factors. External factors can make an impact and initiate a continuous need to enhance productivity and apply innovations to respond to fierce competition. These factors can also be emerging disruptive technologies, barriers to trade, reviewed trade agreements. Internal factors can be capacity building, working culture and motivation, leadership, strategic management, also closely related to decision making processes across different managerial levels and staff generations. Managers variety of attitudes to international trade related elements could cause conflict situations on decision making, damage corporate culture, decrease motivation, slow down international expansion and make a direct impact on diminishing both SMEs productivity and competition.
\end{abstract}

Keywords: exports, export related decisions, international trade, management, decision making, market entry, negotiations, pricing, communication.

JEL Classification: D70, F10.

Conference topic: Internationalization Processes: Contemporary Challenges.

\section{Introduction}

The traditional model of internationalization contains basic ways or development modes such as international trade related (exports/imports), licensing, joint ventures, wholly owned subsidiaries and others. Each of these modes forces companies to create internal capacities to operate numerous activities across different managerial levels. These required capacities are multifold and related to various areas as production, value chain management, productivity, international market expansion, technology interfaces, international teams and many others (Albaum et al. 2016; Bartlett, Beamish 2011; Hamilton, Webster 2015; Geppert, Mayer 2006).

Furthermore, variety of capacities requires to build certain skills of coordination, negotiation, cross cultural communication, continuous improvement, management, marketing, strategy of international business, speed of knowledge in decision making. Thus, it has to involve different managerial levels at companies from one side, on the other hand there is needed an ample, professional and internal potential to manage and satisfy the demand of these skills. As decisions are taken and implemented by involved different levels in structural management, it might cause various views and situation analysis at top, middle and operational management levels. The goal of this paper is to analyze possible gaps in assessment and approach towards international business related decision making elements such as entry modes, pricing and costing and others (Figs 2-5) across different management levels in managerial hierarchies. SMEs in particular can be affected by such situation as they require multitasking approach. Managers can implement and accumulate several functions, limited resources can require skills to carry on several functions, situation in target markets can be seen differently as it was planned and seen from home market at the start. In conclusion, the research analyzes how SMEs different levels managers see the same international trade related decision making element and discovers if there are potential gaps or similarities in these managerial attitudes towards these elements. 


\section{Theoretical background on international trade related decision making across different managerial levels}

International trade is an important competitive factor for nations and business, it facilitates a nation's economy. Companies become more interconnected through the exchange of goods and services, through crucial components as exports/imports and services. As it is essential contribution to competitiveness, companies perceive the increasing importance with their relationship with state institutions (Hamilton, Webster 2015; O'Brien 2016). Among a number of benchmarking indicators as countries performance, exports of goods and services as \% of GDP can demonstrate importance of international trade and export in particular. The smaller the country, the more important indicator is (Fig. 1). Share of exports in GDP also demonstrates interconnection to international markets. In addition, there is a new approach claimed that many companies already are born global. "Born global" approach is used when companies have more than $25 \%$ export in total turnover. Such number is in average $1 / 3$ of all companies. The remaining companies are minor players on international markets or stay locals. But they remain important contributors to economy though (Hill et al. 2014; Schröder 2014; Hamilton, Webster 2015).

Internationalization can be described by four factors such as global, firm, host country and home country markets. Firm factors related are company specific advantages and management interest where global - changes driving internationalization. Such internal and external environment forces companies to respond to challenges where the most critical arise from specific differences such as cultural, legal, marketing environment in a foreign country. Companies possess a variation of practices at management levels where different units are not involved, there is a lack of management, homogenization is demanded as a part of such solutions as standardization, formalization and hierarchic focus of control and accountability (Albaum et al. 2016).

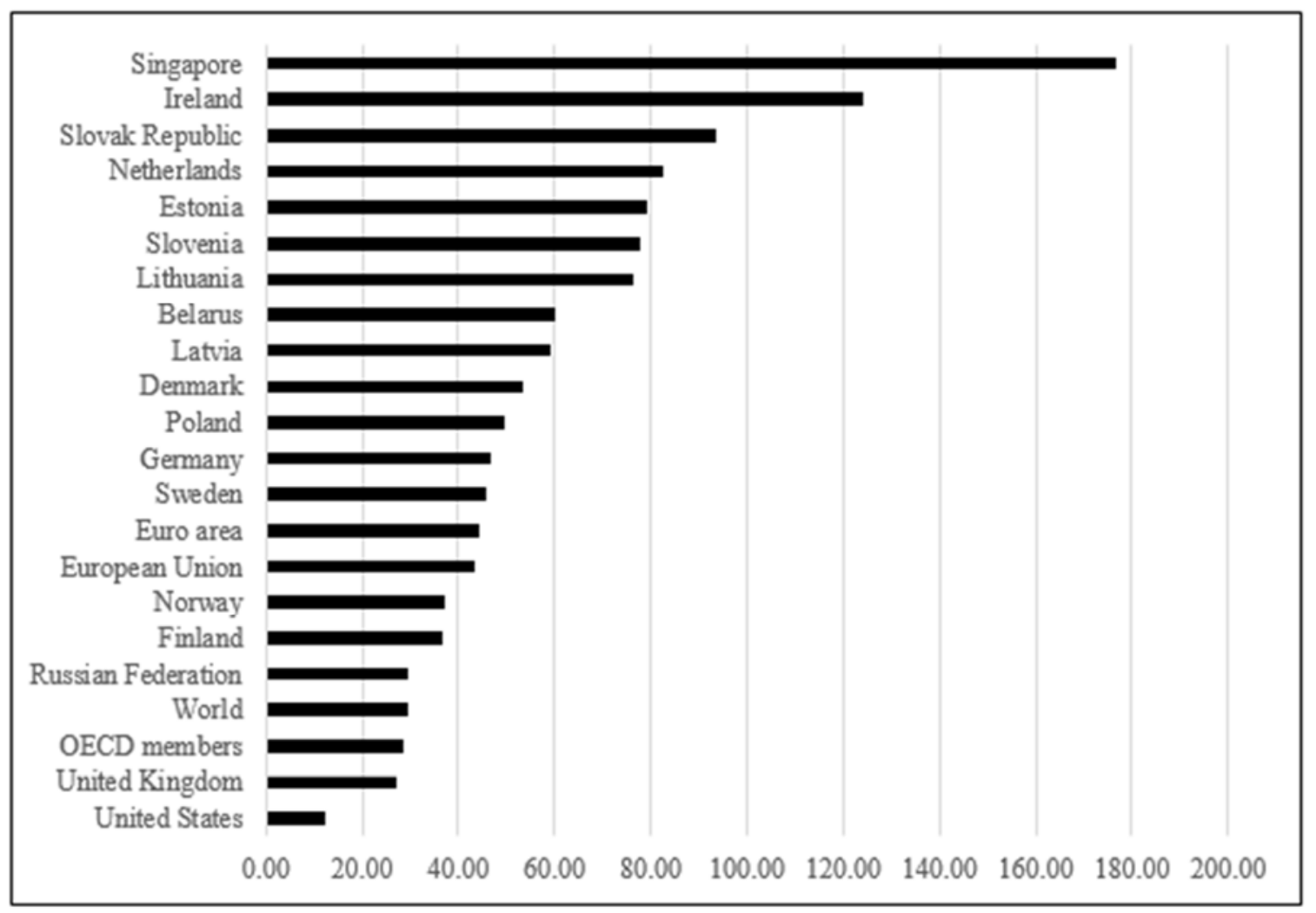

Fig. 1. Exports of goods and services share of GDP, \% (Source: World Bank 2017)

As proven international trade as a part of internationalization is an important key element both for countries economies and SMEs. However, in order to be successful internationally, SMEs have to be professionally structured internally, efficient and competitive. Working across different countries, a number of issues can occur. In order to tackle with difficulties and challenges at hierarchical structures in decision making in international trade related elements, training and management development concepts can be applied. However, it is essential to distinguish these two concepts. Training is related to build special skills in order to do special jobs. Management development is a vital strategic tool. It is aimed to enhance overall skills of different level managers by applied management education, rotation through a number of functions in a company. In order to succeed, unified corporate culture and informal management networks are inherent critical success factors of decision implementation (Albaum et al. 2016; Hill et al. 2014). In addition, countries allocate tangible resources to enhance SMEs export performance through policies such as export promotion programs (EPP) as related to information and financial-aid (Wang et al. 2017). 

the case of SMEs

SMEs are in a focus as a very important area of economy. They compile around $99 \%$ of all enterprises and are significant employers. They also are mostly independent, do not belong to a part of corporate groups and need to tackle with a number of challenges including to accumulate and enhance internal capacities on management (Eurostat 2017).

A concept of being export oriented demands a complex of definite skills in decision making. The survey carried out with Lithuanian SMEs has proven that companies operate across a substantial number of different markets (Table 1). Close to $30 \%$ of companies cover 10 and more export markets. A large number of markets requires professional internal skills to cope with a variety of different markets. A number of critical factors arise as communication externally and within a company.

Table 1. Number of export markets, their share among SMEs and export concentration degree (Source: Brazinskas 2015)

\begin{tabular}{c|c|c}
\hline Number of export markets & Share of number of export markets, $\%$ & Degree of export concentration C \\
\hline 0 & 2 & - \\
2 & 10 & 1 \\
3 & 8 & 0.5 \\
4 & 13 & 0.33 \\
5 & 9 & 0.25 \\
6 & 11 & 0.2 \\
7 & 9 & 0.167 \\
8 & 4 & 0.14 \\
9 & 1 & 0.125 \\
10 and more markets & 4 & 0.11 \\
Total & 29 & 0.1 \\
\hline
\end{tabular}

Internationalization is related to a multifold area of processes, end results and ways of thinking, it involves the entire internal culture of a company. The latter becomes more involved in and committed to serve markets outside its home country through licensing, exporting, manufacturing in a host country and investing (Albaum et al. 2016). Such strategic management requires a variety of skills in leadership, task group formation, organizational culture development, staff motivation, SMART (specific-measurable-achievable-realistic-timely) target settings. According to major management theories, one of the first steps in international business is environment evaluation where the company will operate (McGrath, Bates at. 2013). Management is an important critical factor in international trade. Managers need constantly to monitor own advantages in relation to other locations, it means, work on research, environment analysis and benchmark existing advantages with those which embark in target countries (Peng 2011).

Taking role of internationalization, international trade related components (export) and variety of factors with possible impacts on SMEs development, a hypothesis was given that there can occur attitude differences across managerial levels within a single SMEs. E. g., one of such factors can be cultural antecedents and their impact on decision making process in purchase of foreign or domestic goods where internationally operating managers have to respond to customer behavior and adapt market access strategies to this factor (Conner et al. 2017).

Review of existing trends has caused a need to compile a survey among SMEs to identify hierarchical managers attitudes at international trade related elements by decision making and define possible differences and gaps in these attitudes.

\section{Research methodology and findings on international trade related decision making across different managerial levels}

The research goal was to analyze six international trade related elements and assess how they are seen across different managerial levels at a SME. Data for this study was collected in spring 2016. The survey covered 450 Lithuanian SMEs, three target group managers in a company: top, middle and operational management (Fig. 2).

Top management was represented by CEOs, owners, board members, middle management - by department and division managers and operational management - by export, project, logistic, marketing managers.

The survey was compiled exceptionally on-line with three groups but the same questions. The respondents were asked to express their opinion of a respective part of the survey, each target group answered the same type of standard questions. The response rate has differed among manager levels significantly. Predominating part were top managers as they compile $48 \%$ of all responses. The remaining part equally spread out among middle and operational level manager (around $25 \%$ by each group). 
Such a high level of top manager involvement has shown a high level of their commitment from one hand, on the other hand it can demonstrate several outcomes: 1) SMEs are with limited resources were top managers fulfill a number of functions in a company, 2) top managers can make a significant impact on overall communication control, 3) the survey has proven that there are differences even between managers in the same assigned group (e.g., owners and CEOs in the same company), this is shown below Figure 6 in the comments summary which have been expressed in addition to standard questions of the survey.

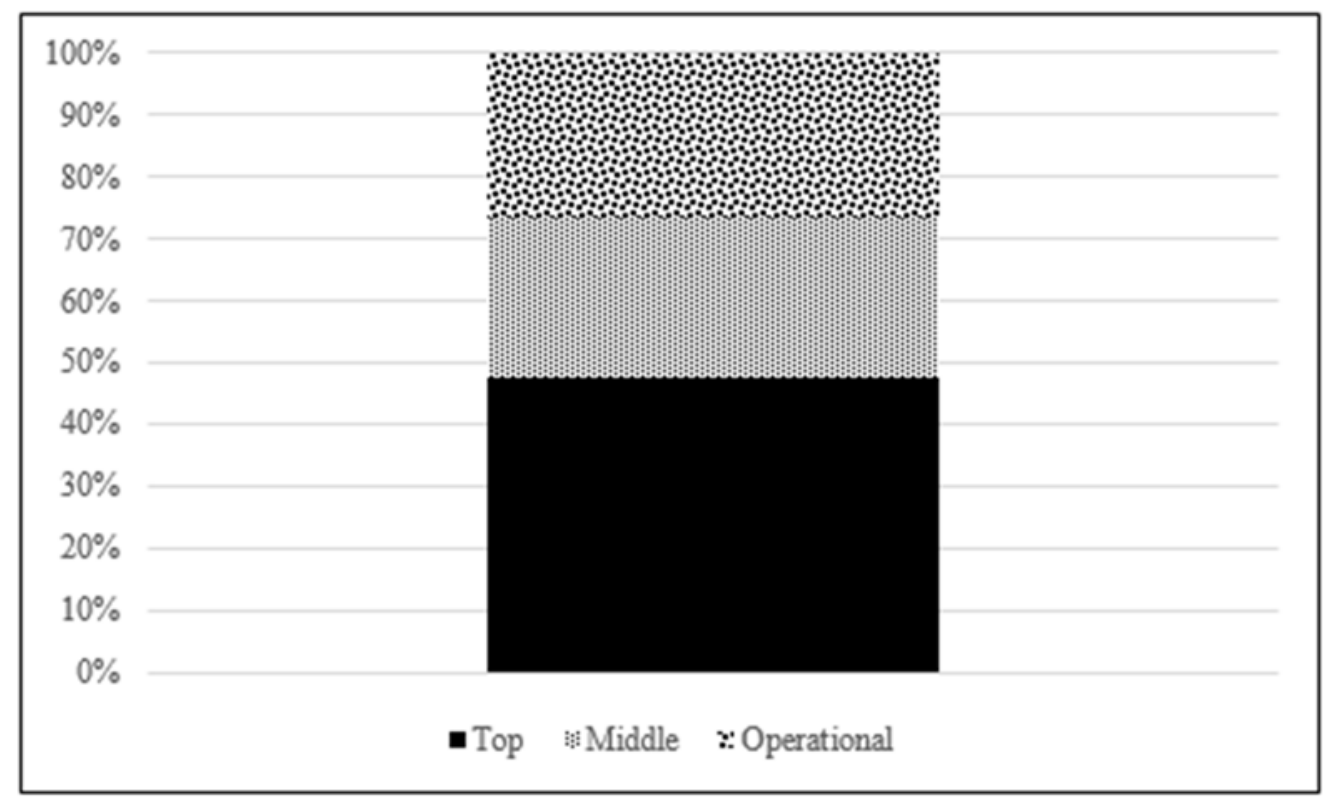

Fig. 2. Manager level groups share by responses in the survey (Source: authors research)

From the one hand the survey aimed to apply a balanced approach towards international trade related elements, on the other hand how decision making can be impacted by ethical, moral and internal culture related elements (Fig. 3). A hypothesis was set up that there is an expectation on different attitudes across different managerial levels where it can cause internal disputes and differences as well as possible conflict situations at SMEs.

International trade related elements (research goal):

1. Entry timing into overseas markets.

2. Pricing and costing.

3. Communication modes with clients overseas.

4. Partner search methods overseas.

5. Market selection methods.

6. Shipment time of cargo to clients abroad.

\section{Decision making related elements:}

1. Strategic management.

2. Environment analysis.

3. Ethical attitudes.

4. Top management involvement.

5. Internal working culture, dialogue, communication, negotiations.

6. Training.

7. Management development.

8. Rotation through various functions.

Fig. 3. Survey goals and balanced approach (Source: authors research)

Personal work and values, cultural backgrounds, consequences on behavioral differences reflect and make a direct impact on decision making process across various corporate levels. Specific standards are applied on individuals despite their managerial positions (Steers et al. 2010). McDonald (2015) investigated, that SMEs very often employ a relatively small number of staff, owners take an active role in management and decision making, they also bring own ethical attitudes to working culture. It happens that price collusion, false advertising unfair pricing are examples. Decision making has a strong ethical dilemma and involves moral awareness, reasoning, defense.

Pricing and costing are defined at a large scale by CEOs. However, they might not know all details in target markets as environment analysis is the critical success factor. If top managers would be asked for certain details about price level, competitors across countries, the managers will often did not provide with a comprehensive feedback on market situation (Simon 2015).

Porter (2008) argues, that top managers have to send right signals to the internal company's community, they also can't oversee and know the situation in a company in depth. On the other hand, they receive information filtered and 
that can cause limited implications and awareness of a situation or market analysis. As a next consequence, there might arise internal conflicts across managerial levels through limited and differently observed information.

While assessing the approach of these six elements, strong negotiation concepts can be considered: business negotiations and analysis of environment, building trust, evidence related (Peleckis 2015). Entry timing and cultural differences are also essential. SMEs are often surprised when they start working on international markets and instead the entry would take months, in fact it takes years. Another important factor is cultural differences which are higher inside a company between managers of different functions then between managers in different countries but with the same functions. E.g., European engineers have more in common with American engineers than with the marketing people in their own company (Bartlett, Beamish 2011). Management across cultures is another important factor. While a company goes overseas, it meets an imminent challenge to work with different cultures. Usually middle and operational managers assure daily communication, they are at the front and the most aware employees to find out market situations. Collaborative decision making process in found in many German, Dutch or Scandinavian firms (Steers et al. 2010). I.e., in target export markets for Lithuanian business. Only these few countries compile more than $20 \%$ of total exports and are the major trading partners (Official statistics portal of Lithuania 2017).

The survey has proven that there are significant differences in decision making when it comes to international trade related elements across different managerial levels (Figs 4-6). However, it is not spread among these elements equally. Responses were grouped in four groups, with significant and important impact were grouped into one, where medium, least and very limited impact in three separate groups (Fig. 6).

Major differences were seen across management levels in following elements:

- Entry timing (duration) into overseas markets. Middle and operational managers stressed that this element is one of the most challenged. Almost $80 \%$ of answers from middle management and $70 \%$ from operational management versus $50 \%$ from top management responded that they see differences in this element when it comes to assessment. As Bartlett investigates (2011), companies top management seek immediate and quick results where the reality is often different, it takes longer than expected;

- Pricing and costing is an element with the most significant difference in relation to remaining five other elements in the survey. Almost $80 \%$ from respondents from middle and operational management expressed a feedback that there are significant differences in treating this element across managerial levels. Only 50\% from top management see that this element causes any issues in different assessment while benchmarking it with other management levels in hierarchical structure of a company;

- Communication with clients overseas has an exceptional feature where operational managers see a major difference against middle and top managers as more than $80 \%$ responded that there are certain differences in attitudes when it comes to communication modes. Collaborative approach, increased diversity of views, solving communication dilemmas, working in teams are among the key success factors to work efficiently across both internal management teams and with overseas partners (Thill, Bovee 2015);

- Partner search and market selection methods are assessed by different managerial levels similarly. In total $50 \%$ of each target group see that these elements create differences in attitudes but these elements are seen with the lowest impact on decision making. Brazinskas (2015) indicated that more that $60 \%$ of companies place priority on in geographic proximity situated neighboring markets;

- Shipment as a crucial international trade related element does not cause significant differences in managers attitudes across hierarchy. This element varies similarly in a range of $60 \%$ of respondents as an important element, thus it is treated equally important in terms of attitude of decision making.

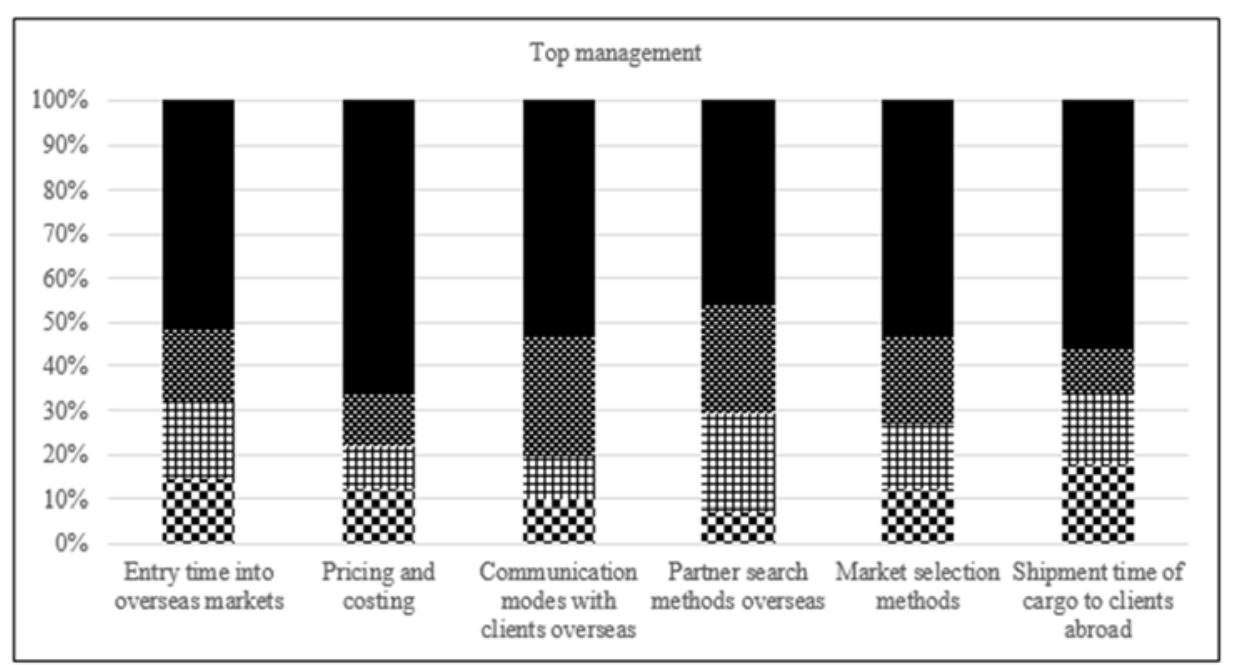

Fig. 4. Top management attitude to decision making elements (Source: own research) 


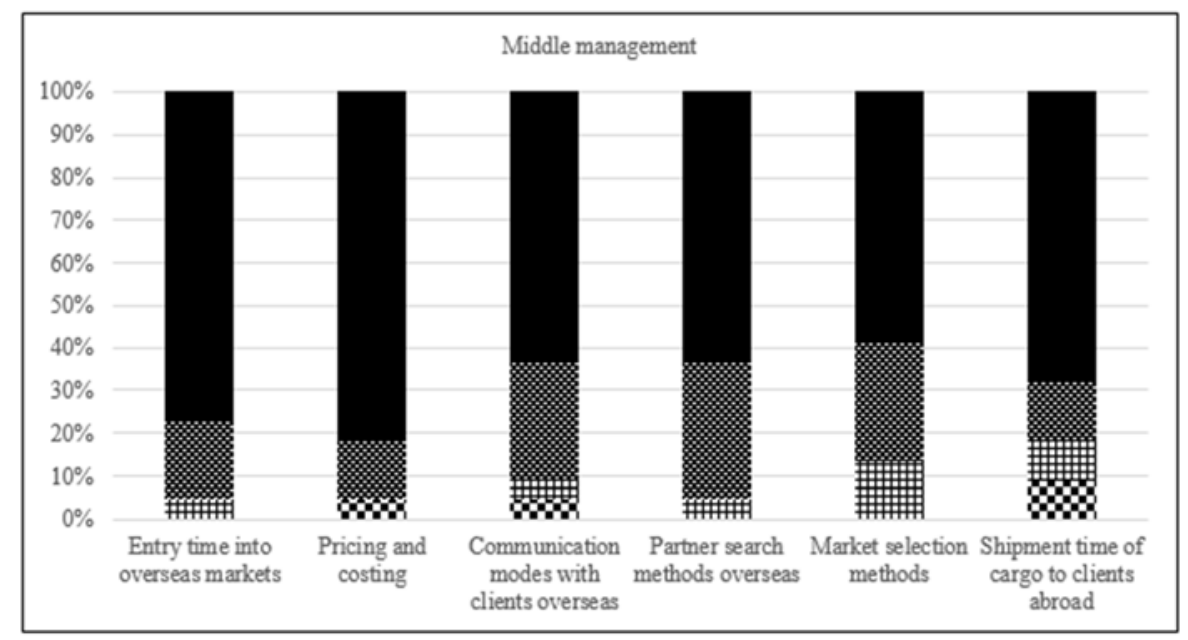

Fig. 5. Middle management attitude to decision making elements (Source: own research)

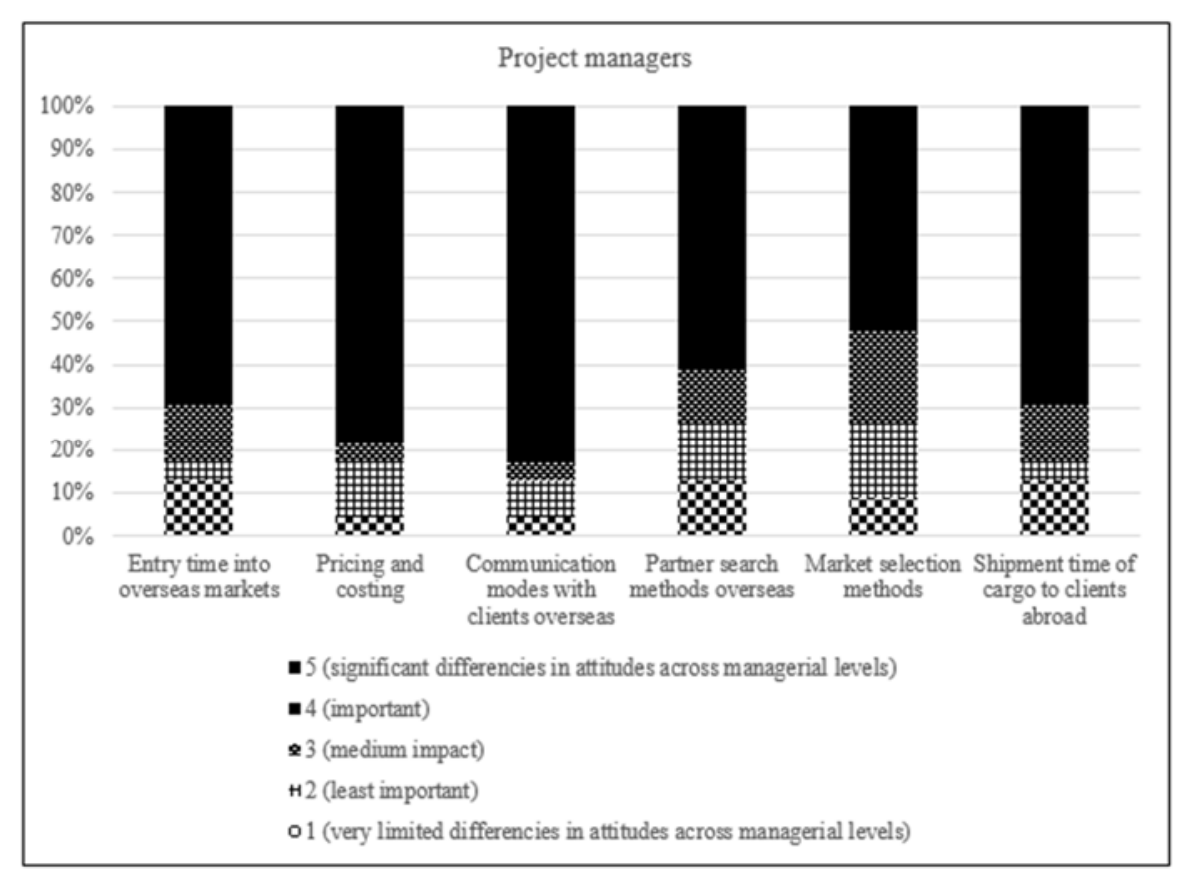

Fig. 6. Project managers attitude to decision making elements (Source: own research)

In addition to standard questions all managers were asked to provide with any comments which would complement and enhance the importance of the feedback. This is also an essential part which demonstrates a variety of internal situations and differences at the same international trade related elements. Comments also gave a feedback on views differences between owners and hired managers as they were treated as one single group as top managers.

Summarized feedbacks by top level managers:

- Owners and CEOs possess different attitudes towards expenditures related to export marketing and overall activities in foreign target markets (CEOs aim to allocate larger amounts),

- Owners can treat their company internal divisions not interconnected among themselves as one single and common company by achieving goals to grow overseas. An example was given that the production unit does not need to be improved in terms of a positive image in the view of foreign partners and expose more opportunities given by the company.

Middle level managers expressed following comments in companies which cause differences in attitudes regarding international trade related elements:

- Internal differences towards appropriate investments to penetrate foreign markets,

- Competence and work attitude differences among various levels of company's employees. 
Foreign markets establishment, long term partnership, compliance to international management standards build a complex of trade related elements (Slepniov et al. 2013). This research has proven that there are obvious differences among top, middle and operational managers while assessing these elements. The research analyzed six of them (Figs 4-6). The biggest disparities and possible conflicts are visible at entry timing, pricing and costing and communication modes. These elements in particular prove hypothesis that specific and certain elements are more important that other. These elements have to attract higher attention in strategic management on decision making. If there are significant differences by managers, such situations can cause internal conflicts and diminish company's culture as well as make a direct impact on overall productivity and competitiveness. All three target managers group have similar views at partner search, market selection and shipment time as least impact on decision making process.

\section{Conclusions}

The paper examines the topic of six elements related to international trade development with a direct impact to SMEs growth and competitiveness across 450 Lithuanian SMEs. These elements are enablers of competitive advantages built inside the company. However, on the other hand they can cause a number of internal issues across different managerial levels if they are considered differently. The goal of this survey was namely to look and analyze approaches of different managers at specific individual element such as pricing and costing, market selection mode, entry time, communication, partner search and shipment. Results have shown that the highest difference among managers is seen towards entry time into overseas markets, communication modes and pricing and costing. Here middle and project managers attitude is substantially different from top managers. It is obvious, top management can expect much more quicker results, but they also can be misled by existing gap and lack of awareness of direct situation in market conditions and clients behavior as well as expectations. The survey has open the gap as there are significant differences among various managers levels in company not only to elements in the survey but even wider (culture, work competence). This can be a part of further research to look much wider in international trade related elements and their role in decision making.

In order to strengthen internal corporate culture and foster international trade related decision making process, following recommendations to SMEs can be offered: 1) management development has to be become a strategic tool; 2) in-company training can be initiated with specific topics related to six elements (Figs 4-6), e.g., negotiation, market research, basics in costing and other; 3) specific external training sessions can be attended to benchmark different situations and share best practice with other companies; 4) integration into management networks can be implemented, both as off-line as well as on-line; 5) managers rotation through a number of functions can be launched; 6) hired external consultants with best practice approach can contribute to internal management development.

The study has a number of limitations, which were beyond of this paper's scope to address. First, the sectorial approach of SMEs was not analyzed. Second, authors did not analyze the scope of each specific element by target group where each of them could have different understanding on analysis width. Third, there are several methodological challenges such as on-line form application and feedback expressed on a remote mode, degree of involvement of each managerial level in each element analysis, limited number of analyzed elements. Forth, analysis can cause identified gaps in competence demand and it has not been analyzed within this survey.

It is strongly believed that findings and conclusions may be useful in informing SMEs on international trade related elements, strengthen company's internal culture, enhance negotiation skills among employees, foster dialogue among different managerial levels within SMEs, identify the most suitable modes by applying specific elements and unite expectations of managers by applied elements and implementation. The results can also inspire further need on benchmarking to assess performance of different companies and strengthen networking and knowledge transfer. It can also show gaps.

The variety of elements of decision making in international trade development can be key factors for SMEs to consider, apply in companies with the next impact to enable SMEs to expand and grow internationally.

\section{References}

Albaum, G.; Duerr, E.; Josiassen, A. 2016. International marketing and export management. Essex: Pearson Education, $483-532$.

Bartlett, Ch. A.; Beamish, P. W. 2011. Transnational Management. $6^{\text {th }}$ ed. New York: McGraw Hill, 560-565.

Brazinskas, S. 2015. Foreign market selection methods in a changing international trade environment: the case of Lithuanian SMEs. VGTU Press, in The $4^{\text {th }}$ International Scientific Conference "Contemporary Issues in Business, Management and Education 2015”, Vilnius, Lithuania. https://doi.org/10.3846/cibme.2015.09

Conner, S. L.; Reardon, J.; Miller, Ch.; Salciuviene, L.; Auruskeviciene, V. 2017. Cultural antecedents to the normative, affective, and cognitive effects of domestic versus foreign purchase behavior, Journal of Business Economics and Management 18(1): 100-115. https://doi.org/10.3846/16111699.2016.1220975

Eurostat. 2017. Dependent and independent SMEs and large enterprises [online], [cited 14 February 2017]. Available from Internet: http://ec.europa.eu/eurostat/statistics-explained/index.php/Statistics_on_small_and_medium-sized_enterprises

Geppert, M.; Mayer, M. 2006. Global, national and local practices in multinational companies. New York: Palgrave, $105-163$.

Hamilton, L.; Webster, Ph. 2015. The international business environment. Oxford: Oxford University Press, 38-65. 
Hill, Ch.; Udayasankar, K.; Hou, W. Ch. 2014. Global business today. McGraw-Hill Education, 478-489.

McDonald, G. 2015. Business ethics. Melbourne: Cambridge University Press, 345-350.

McGrath, J.; Bates, B. 2013. The little book of big management theories and how to use them. Harlow: Pearson, 104-124.

O'Brien, B. 2016. 10 small countries who are major players in the international trade world [online], [cited 14 February 2017]. Available from Internet: www.tradeready.ca/2016/topics/researchdevelopment/10-small-countries-major-players-international-trade-world/

Official statistics portal of Lithuania [online], 2017 [cited 14 February 2017]. Available from Internet: http://osp.stat.gov.lt/temineslenteles 43

Peleckis, K. 2016. Business negotiations: communication in bargaining process: Monograph. North Charleston: Create Space.

Peng, M. 2011. Global. Mason: South-Western Cengage Learning, 10-50.

Porter, M. 2008. On competition. Harvard business review, 508-525.

Schröder, Ph. 2014. Hemmeligheden bag en eksportsuccess, Eksportfokus 1: 47.

Simon, H. 2015. Confessions of the pricing man. How price affects everything. Heidelberg: Springer International Publishing Switzerland, 208-210. https://doi.org/10.1007/978-3-319-20400-0

Slepniov, D.; Brazinskas S.; Wæhrens, B. V. 2013. Nearshoring practices: an exploratory study of Scandinavian manufacturers and Lithuanian Vendor Firms, Baltic Journal of Management 8(1): 5-26. https://doi.org/10.1108/17465261311291632

Steers, R. M.; Sanchez-Runde, C. J.; Nardon, L. 2010. Management across cultures. Cambridge: Cambridge University Press, 140157. https://doi.org/10.1017/CBO9780511810510

Thill, J. V.; Bovee, L. C. 2015. Excellence in business communication. Essex: Pearson Education, 10-50.

Wang, X.; Chen, A.; Wang, H.; Li, S. 2017. Effect of export promotion programs on export performance: evidence from manufacturing SMEs, Journal of Business Economics and Management 18(1): 131-145. https://doi.org/10.3846/16111699.2016.1278031

World Bank. 2017. Exports of goods and services (\% of GDP) [online], [cited 14 February 2017]. Available from Internet: http://data.worldbank.org/indicator/NE.EXP.GNFS.ZS 